\title{
Avaliação da Resistência Mecânica de Soldas de Filete Seguindo Especificações da Norma NBR 8800-2008
}

\author{
Maicon Roberto Teodoro ${ }^{1,2}$ (D), Rogério Varavallo ${ }^{3}$ (D), Henrique Boschetti Pereira ${ }^{4}$ (D), Marcos Dorigão Manfrinato ${ }^{1,2}$ (D) , Luciana Sgarbi Rossino ${ }^{1,2}$ (D) \\ ${ }^{1}$ Faculdade de Tecnologia José Crespo Gonzales - FATEC Sorocaba, Sorocaba, SP, Brasil. \\ ${ }^{2}$ Universidade Federal de São Carlos - UFSCar, Programa em Pós-graduação em Ciência dos Materiais, Sorocaba, SP, Brasil. \\ ${ }^{3}$ Escola Técnica Estadual Sylvio de Mattos Carvalho - ETEC, Matão, SP, Brasil. \\ ${ }^{4}$ Universidade de São Paulo - USP, Escola Politécnica, Departamento de Engenharia Metalúrgica e de Materiais, São Paulo, SP, Brasil.
}

Como citar: Teodoro MR, Varavallo R, Pereira HB, Manfrinato MD, Rossino LS. Avaliação da resistência mecânica de soldas de filete seguindo especificações da norma NBR 8800-2008. Soldagem \& Inspeção. 2021;26:e2603. https://doi.org/10.1590/0104-9224/SI26.03

\begin{abstract}
Resumo: Ao analisar a norma ABNT NBR 8800-2008, foi constatado que não há consideração sobre a tensão ou compressão exercida nas regiões soldadas por filetes. O cálculo para dimensionamento de perna só leva em referência o cisalhamento da seção. Utilizando recursos como a simulação e o ensaio mecânico de tração, foi possível comparar as dimensões mínimas das pernas com a estipulada pela norma NBR. Realizou-se o processo de soldagem com eletrodo revestido, utilizando o aço estrutural ASTM A36, e para realização da soldagem foi empregado o eletrodo AWS A5.1 E7018. As soldagens focaram com tamanho de filetes com perna entre $3,5 \mathrm{~mm}$ e $7 \mathrm{~mm}$ que posteriormente estas juntas soldadas foram submetidas a ensaios de tração. Para a comparação dos resultados, foi empregado simulação numérica

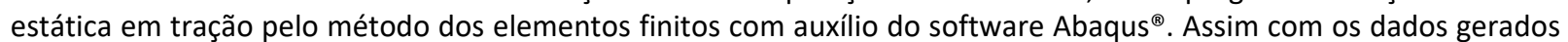
através da simulação e o ensaio mecânico de tração pode-se legitimar as especificações da norma em relação ao tamanho mínimo de perna em relação à espessura da chapa.
\end{abstract}

Palavras-chave: Solda em filete; Aço; ABNT NBR 8800-2008; Propriedades mecânicas.

\section{Evaluation of Fillet Welds Mechanical Properties according to NBR 8800- 2008 Standard Specifications}

\begin{abstract}
It was found that there is no consideration of the tensile or compression stresses applied in the regions of fillet weld when analyzing the ABNT NBR 8800-2008 standard. The calculation for dimensioning the leg only takes into account the section shear. Using resources such as simulation and mechanical traction test, it was possible to compare the minimum dimensions of the legs with that stipulated by the NBR standard. The welding process was carried out with a coated electrode, using structural steel ASTM A36, and the welding was performed using the AWS A5.1 E7018 electrode. Tensile testing were performed on fillet welding samples with lengths between $4 \mathrm{~mm}$ and $8 \mathrm{~mm}$. It was used a numerical simulation in traction by the finite element method was used with the aid of the Abaqus ${ }^{\circledR}$ software. Thus, with the data generated through the simulation and the mechanical tensile test, the specifications of the standard can be assured in relation to the minimum leg size in relation to the plate thickness.
\end{abstract}

Key-words: Fillet weld; Steel; ABNT NBR 8800-2008; Mechanical properties.

\section{Introdução}

Ligação em resistência de materiais é a união entre dois membros ou peças em qualquer tipo de estrutura, os processos que não envolvem o aporte de energia são aqueles que ocorrem por meio de uma união mecânica (parafusos e rebites) ou pela adesão com alguma substância aglutinante (colagem), já os processos em que ocorrem a união de dois ou mais materiais com fornecimento de energia, criando um meio metálico contínuo, são denominados de processos de soldagem [1,2]. Dimensionar corretamente juntas soldadas sobre estruturas metálicas pode evitar falhas, eventualmente catastróficas, além de reduzir significativamente custos e distorções [3]. A resistência da solda de filete, segundo a NBR 8800:2008 [4], aborda projeto de estruturas metálicas, onde a norma determina requisitos de projeto a fim de garantir a confiabilidade e sua integridade. $A$ resistência da solda de filete é determinada pelo tamanho mínimo da perna, este é determinado pela equação prescrita pela norma. Perna do filete (b) é o menor dos dois lados, situados na face de fusão, do maior triângulo que pode ser inscrito na seção da solda, conforme ilustrado na Figura $1[5]$ 


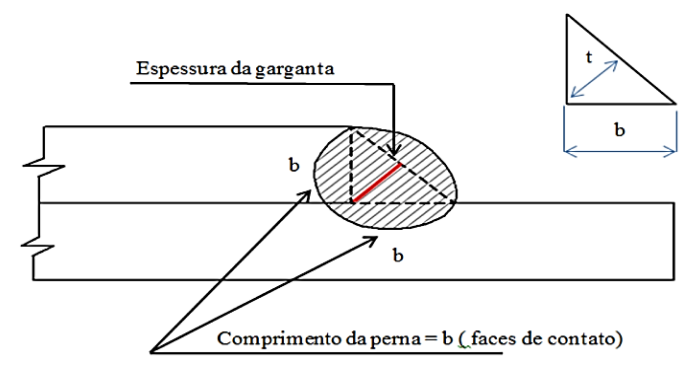

Figura 1. Representação da perna de filete. Adaptado de [5].

As soldas de filetes são assimiladas, para efeito de cálculo, ao triângulo retângulo. Os filetes são designados pelo comprimento de seus lados [6,7]. Portanto, um filete de $8 \mathrm{~mm}$ contém seus lados representado por (b) igual a $8 \mathrm{~mm}$, já um filete de (6x10) $\mathrm{mm}$ designa que um de seus lados possui $6 \mathrm{~mm}$ e outro $10 \mathrm{~mm}$.

Dependendo da geometria do filete, principalmente se a parte exterior da soldagem for côncava ou convexa, a garganta efetiva de filete pode ser determinada conforme a plotagem do maior triângulo possível, sendo que dois de seus segmentos devem coincidir com a superfície do metal anterior à solda. A garganta efetiva corresponde a menor seção retilínea partindo do vértice (ponto entre as duas seções do metal base) em contraponto à seção oposta $t$ [2], como se pode observar na Figura 2.

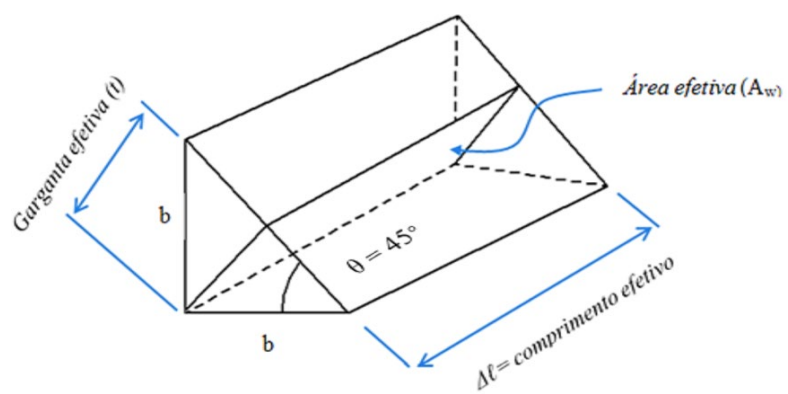

Figura 2. Ilustração do filete de solda com lados " $b$ " iguais e ângulo de $45^{\circ}$ [5].

Para realizar os cálculos da garganta teórica da Figura 2, utilizamos a Equação 1 [5].

$\operatorname{sen} 45^{\circ}=\frac{t}{b} \rightarrow t=\frac{\sqrt{2}}{2} * b=0,707 * b$

Já para calcular a área efetiva $(A w)$ de soldas com os lados (b) semelhantes, utilizamos a Equação 2 [5].

$A w=0,707 b * l$

Quando não é possível obter lados congruentes na formação do triângulo, como ilustrado na Figura 3, o cálculo da garganta do cordão de solda $t$ é apresentada na Equação 3 [2].

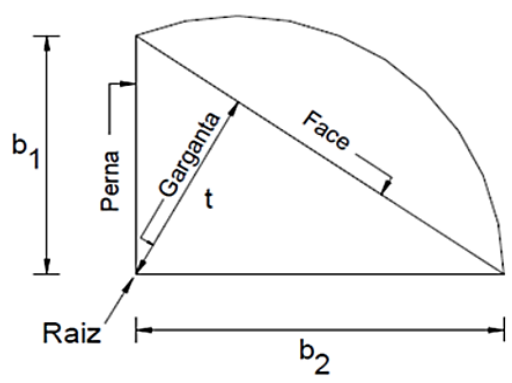

Figura 3. Pernas do cordão de solda com tamanhos de pernas diferentes [2].

$t=\frac{b 1+b 2}{\sqrt{b 1^{2}+b 2^{2}}}$ 
A área efetiva para pernas diferentes é apresentada na Equação 4 [2].

$A w=t * l$

A hipótese de tensão uniforme significa que, se for cortada uma barra na seção bem distante das extremidades e eliminarmos um pedaço, pode-se substituir seu efeito pela aplicação de uma força uniformemente distribuída de magnitude ( $\sigma \cdot A$ ) na extremidade cortada. Assim, a tensão $\sigma$ é uniformemente distribuída [8] e pode ser calculada pela Equação 5.

$\sigma=\frac{F}{A}$

Este trabalho aborda experimentalmente e por métodos de elementos finitos a definição de perna mínima de solda em chapas sobrepostas.

\section{Materiais e Métodos}

Para determinar a dimensão da garganta e do filete de solda foi utilizada a norma NBR 8800:2008 [4]. O tamanho da perna do filete é associado com a espessura do metal de base; sendo o tamanho da perna responsável pelo cálculo da garganta da solda que determina a resistência da mesma. A Tabela 1 indica o tamanho mínimo da perna pela espessura do metal de base. Neste trabalho foi utilizado o metal de base, aço estrutural ASTM A36 [9] de espessura 9,5 mm, e, de acordo com a norma, o tamanho mínimo da perna de solda deve ser de pelo menos $5 \mathrm{~mm}$ [4]. Não obstante, com o objetivo de analisar a influência de diferentes tamanhos de perna, foram realizadas soldagens com valores diferentes do especificado em norma.

Tabela 1. Orientação das dimensões mínimas da perna de filete pela espessura do metal base conforme ABNT NBR 8800:2008 [4]

\begin{tabular}{cc}
$\begin{array}{c}\text { Menor espessura do metal-base na junta } \\
(\mathbf{m m})\end{array}$ & $\begin{array}{c}\text { Tamanho mínimo de perna da solda de filete, } \mathbf{d}_{\mathbf{w}}{ }^{{ }^{2}} \\
(\mathbf{m m})\end{array}$ \\
Abaixo de 6,35 e até 6,35 & 3 \\
Acima de 6,35 até 12,5 & 5 \\
Acima de 12,5 até 19 & 6 \\
Acima de 19 & 8 \\
\hline
\end{tabular}

a executadas somente com um passe.

O cordão de solda foi realizado conforme especificação da norma NBR 8800:2008 [4] com o metal de adição de classificação AWS A5.1 E7018 [10]. Não obstante, com o objetivo de analisar a influência de diferentes tamanhos de perna, foram realizadas soldagens com valores diferentes do especificado em norma. A característica mecânica de resistência à ruptura do aço estrutural ASTM A36 [9] é de $400 \mathrm{MPa}$ a $550 \mathrm{MPa}$ e do eletrodo revestido AWS A5.1 E7018 [10] é de, no mínimo, 485 MPa.

A tensão de cisalhamento na seção efetiva esta apresentada na Tabela 2. Entretanto neste trabalho foi abordado as tensões de tração e de compressão no eixo da solda, pois a norma desconsidera os ensaios para o dimensionamento das pernas.

Tabela 2. Reprodução parcial das especificações do tipo de solda e como deve ser calculada a resistência, conforme ABNT NBR 8800:2008 [4].

\begin{tabular}{|c|c|c|}
\hline Tipo de solda & Tipo de solicitação e orientação & Força resistente de cálculo $F_{\mathrm{w}, \mathrm{Rd}}$ \\
\hline \multirow{4}{*}{ Penetração total } & Tração ou compressão paralelas ao eixo da solda & Não precisa ser considerada \\
\hline & Tração ou compressão normal à seção efetiva da solda & Metal base: $\mathrm{A}_{\mathrm{MB}} f / \mathrm{Y}_{\mathrm{a} 1}$ \\
\hline & Cisalhamento (soma vetorial) na seção efetiva & Metal base: $0,60 \mathrm{~A}_{\mathrm{MB}} f / \mathrm{Ya}_{\mathrm{a}}$ \\
\hline & Tração ou compressão paralelas ao eixo da solda & Não precisa ser considerada \\
\hline \multirow{4}{*}{ Penetração parcial } & & A menor dos dois valores: \\
\hline & Tração ou compressão normal à seção efetiva da solda & Metal base: $\mathrm{A}_{\mathrm{MB}} f_{\mathrm{y}} / \mathrm{\gamma}_{\mathrm{a} 1}$ \\
\hline & & Metal de solda: $0,60 \mathrm{~A}_{\mathrm{w}} f_{\mathrm{w}} / \gamma_{\mathrm{w} 1}$ \\
\hline & Cisalhamento paralelo ao eixo da solda, na seção efetiva & $\begin{array}{l}\text { Metal base deve atender a } 6.5 \\
\text { Metal de solda: } 0,60 \mathrm{~A}_{\mathrm{w}} f \mathrm{w} / \gamma_{\mathrm{w} 2}\end{array}$ \\
\hline \multirow{3}{*}{ Filete } & Ração ou compressão paralelas ao eixo da solda & Não precisa ser considerada \\
\hline & $\begin{array}{l}\text { Cisalhamento na seção efetiva (a solicitação é igual à } \\
\text { resultante vetorial de todas as forças de cálculo na junta que }\end{array}$ & Metal base deve atender a 6.5 \\
\hline & $\begin{array}{l}\text { produzam tensões normais ou de cisalhamento na superfície } \\
\text { de contato das partes ligadas) }\end{array}$ & Metal de solda: $0,60 \mathrm{~A}_{\mathrm{w}} f_{\mathrm{w}} / \gamma_{\mathrm{w} 2}$ \\
\hline \multirow{2}{*}{ Tampão em furos ou rasgos } & Cisalhamento paralelo às superfícies em contato, na seção & Metal base deve atender a 6.5 \\
\hline & efetiva & Metal de solda: $0,60 \mathrm{~A}_{\mathrm{w}} f_{\mathrm{w}} / \gamma_{\mathrm{w} 2}$ \\
\hline
\end{tabular}


As dimensões dos corpos de prova foram definidas segundo a NBR 8800:2008 [4], e estão apresentadas na Figura 4.

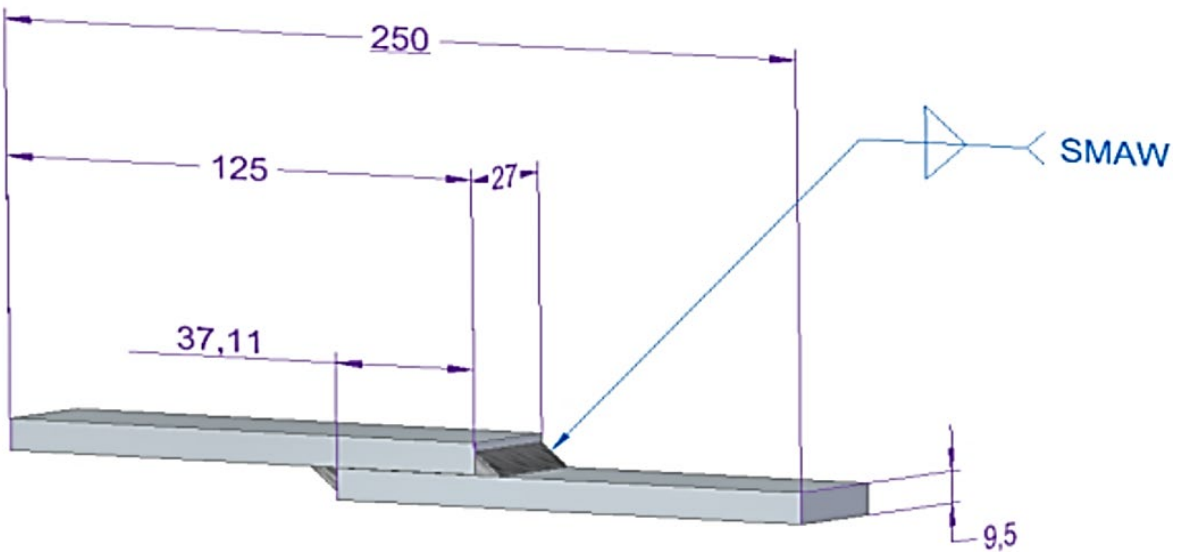

Figura 4. Ilustração da geometria dos corpos de prova de tração de junta sobreposta.

Para o dimensionamento da perna foi utilizado como referência dados encontrados na Tabela 1 e ilustrada na Figura 4.

- $\quad$ Corpos de prova CP 1, CP 2 e CP 3 com o tamanho da perna menor que 3,5 mm.

- $\quad$ Corpos de prova CP 4, CP 5 e CP 6 com o tamanho da perna maior que $7 \mathrm{~mm}$.

Apesar do valor especificado, a parte prática envolve desvios naturais do processo de soldagem. Porém, a média e desvio padrão do tamanho de perna dos primeiros 3 corpos de prova foi de 4,5 $(1,4)$ e para os últimos 3 corpos de prova foi de $6,9(0,6)$

Os corpos de prova foram submetidos à tração, utilizando uma pré-carga de $3 \mathrm{kN}$ e velocidade de deslocamento de 2 $\mathrm{mm} / \mathrm{min}$.

Os ensaios metalográficos da junta soldada foram realizados com o auxílio de um microscópio óptico. Foi utilizado o mesmo corpo de prova antes do ensaio de tração para a realização dos exames metalográficos. Estas amostras foram lixadas, polidas, atacadas e fotografadas antes do ensaio de tração. A análise microestrutural foi realizada com auxílio de um microscópio óptico da marca Leica modelo DMi8M com câmera acoplada da marca Leica DFC365 Fx com resolução de 1,4 MP e software de captura LAS com pacote Quantimet da Leica, pertencente ao Laboratório de Microscopia da Fatec Sorocaba.

As simulações numéricas dos ensaios de tração foram realizadas pelo software Abaqus ${ }^{\circledR}$ que utiliza o método dos elementos finitos. Este método utiliza a discretização de geometrias (geralmente complexas) em elementos definidos que respondem de acordo com o cálculo de equações fundamentais de reação entre cada elemento.

O modelo considerou corpos e prova com pernas de $4 \mathrm{~mm}$ a $7 \mathrm{~mm}$, avançando o tamanho de perna de $1 \mathrm{~mm}$ em $1 \mathrm{~mm}$, com o objetivo de verificar como a distribuição de tensões evolui. Como as chapas possuíam $(25,0 \times 9,5) \mathrm{mm}^{2}$, foi considerada a fonte de força para o máximo de acordo com o definido em norma, simulando as garras de máquina de tração. A malha do modelo foi desenvolvida com 3519 nós e 2384 elementos hexaédricos do tipo C3D8R.

Conforme a tensão mínima necessária para a aprovação da norma ABNT NBR 8800:2008 de 438 MPa, foi considerada uma força vertical estática de $110 \mathrm{kN}$. As propriedades mecânicas elásticas e plásticas foram retiradas dos ensaios de tração, sendo considerado módulo de elasticidade $(E)$ de 205 GPa e coeficiente de Poison ( $v$ ) de 0,3.

Não foi considerado heterogeneidade microestrutural e, consequentemente, de propriedades mecânicas geradas pelas transformações de fases devido ao ciclo térmico do processo de soldagem. O corpo de prova simulado foi considerado homogêneo e isotrópico de acordo com as geometrias especificadas anteriormente.

Ensaios de líquido penetrante foram realizados nos corpos de prova soldados antes do ensaio de tração e após o ensaio de tração que não romperam na solda, para comparação com os resultados obtidos na simulação.

\section{Resultados e Discussões}

Observam-se, nas análises macrográficas ilustradas na Figura 5, as dimensões das pernas e das gargantas de cada corpo de prova. Evidencia-se os dados que foram obtidos após o processo de soldagem e explicitam a difícil tarefa de manter os valores esperados com os realizados. Não obstante, a média foi dentro do esperado. Nesses exames macrográficos, ficou evidente que no corpo de prova 3 (Figura 5-f) houve a formação de inclusões e/ou porosidade no interior da zona fundida. Estas descontinuidades afetam categoricamente a resistência mecânica das juntas soldadas devido à diminuição de seção resistente e possível sítio de nucleação de trincas; no entanto, estas soldas foram mantidas para visualizar a resistência mecânica global, independente dos defeitos observados. 


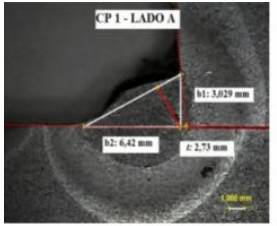

(a)

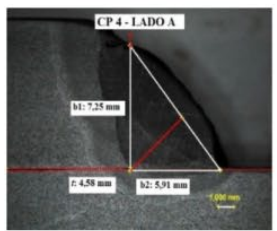

(g)

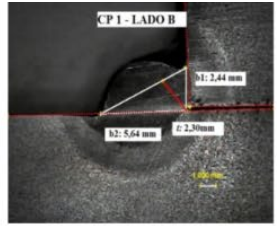

(b)

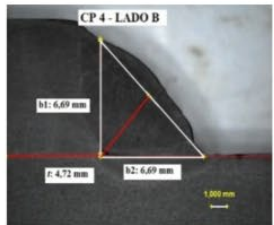

(h)

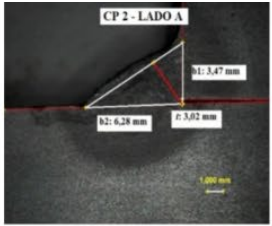

(c)

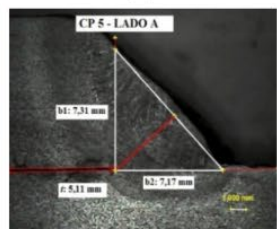

(i)

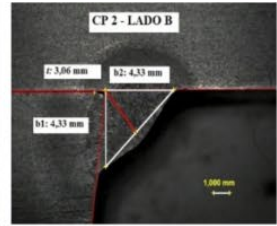

(d)

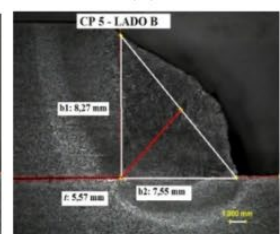

(j)

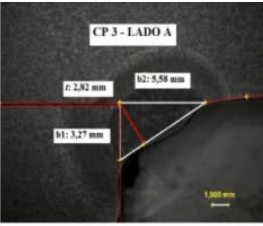

(e)

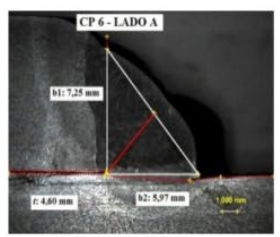

(k)

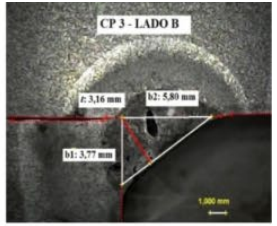

(f)

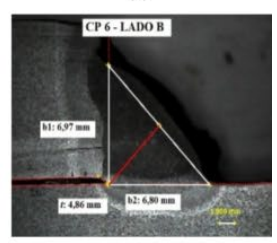

(1)

Figura 5. Macrografia da secção transversal do cordão de solda dos corpos de prova soldado. (a) CP1 lado $A$, (b)CP1 lado $B$, (c) CP2 lado $A$, (d) CP2 lado B, (e) CP3 lado A, (f) CP3 lado B, (g) CP4 lado A, (h) CP4 lado B, (i) CP5 lado A, (j) CP5 lado B, (k) CP6 lado A, (I) CP6 lado B.

Na Tabela 3 estão correlacionadas as medidas de pernas e gargantas de cada amostra. Observa-se que há um desvio padrão alto em relação às pernas, tal desvio ocorre porque a solda é realizada por um operador, dificilmente a operação iria ter medidas exatas; mas como foi previsto, todas as medidas estão correlacionadas com o tamanho mínimo da perna do filete mostrada na Tabela 3. Foram relacionados os corpos de prova como CP 1 , 2 e 3 menores que $5 \mathrm{~mm}(4,5 \pm 1,4)$ e CP 4,5 e 6 maiores que $5 \mathrm{~mm}$ $(6,9 \pm 0,6)$.

Tabela 3. Valores das pernas e garganta do cordão de solda para as condições soldadas. Valores teóricos utilizados nos cálculos de resistência.

\begin{tabular}{|c|c|c|c|c|c|c|c|c|c|c|c|c|}
\hline & \multicolumn{2}{|c|}{ CP1 } & \multicolumn{2}{|c|}{ CP2 } & \multicolumn{2}{|c|}{ CP3 } & \multicolumn{2}{|c|}{ CP4 } & \multicolumn{2}{|c|}{ CP5 } & \multicolumn{2}{|c|}{ CP6 } \\
\hline & A & B & A & B & A & B & A & B & A & B & A & B \\
\hline b1 (mm) & 3,02 & 2,44 & 3,47 & 4,33 & 3,27 & 3,77 & 7,25 & 6,69 & 7,31 & 8,27 & 7,25 & 6,97 \\
\hline b2 (mm) & 6,42 & 5,64 & 6,28 & 4,33 & 5,58 & 5,8 & 5,91 & 6,69 & 7,71 & 7,55 & 5,97 & 6,8 \\
\hline $\mathrm{t}(\mathrm{mm})$ & 2,73 & 2,3 & 3,02 & 3,06 & 2,82 & 3,16 & 4,58 & 4,72 & 5,11 & 5,57 & 4,6 & 4,86 \\
\hline$S(b)$ & \multicolumn{2}{|c|}{1,95} & \multicolumn{2}{|c|}{1,19} & \multicolumn{2}{|c|}{1,27} & \multicolumn{2}{|c|}{0,55} & \multicolumn{2}{|c|}{0,49} & \multicolumn{2}{|c|}{0,55} \\
\hline$S(t)$ & \multicolumn{2}{|c|}{0,3} & \multicolumn{2}{|c|}{0,03} & \multicolumn{2}{|c|}{0,24} & \multicolumn{2}{|c|}{0,1} & \multicolumn{2}{|c|}{0,33} & \multicolumn{2}{|c|}{0,18} \\
\hline $\bar{X}(\mathrm{~b})$ & \multicolumn{2}{|c|}{4,38} & \multicolumn{2}{|c|}{4,6} & \multicolumn{2}{|c|}{4,61} & \multicolumn{2}{|c|}{6,64} & \multicolumn{2}{|c|}{7,58} & \multicolumn{2}{|c|}{6,75} \\
\hline $\bar{X}(\mathrm{t})$ & \multicolumn{2}{|c|}{2,52} & \multicolumn{2}{|c|}{3,04} & \multicolumn{2}{|c|}{2,99} & \multicolumn{2}{|c|}{4,65} & \multicolumn{2}{|c|}{5,34} & \multicolumn{2}{|c|}{4,73} \\
\hline
\end{tabular}

Os cálculos gerados através da literatura estão representados na Tabela 4, na qual se denota que os CPs 1,2 e 3 romperamse no cordão de solda, pois as tensões na região soldada são maiores que a tensões exercidas no metal base. Agora para os CPs 4,5 e 6 a tensão exercida no cordão é menor que a tensão distribuída no corpo de prova, assim o rompimento ocorrera no corpo de prova.

Tabela 4. Valores das médias das pernas e da garganta dos filetes de solda e resistência de cálculo do metal de base.

\begin{tabular}{|c|c|c|c|c|}
\hline Corpo de prova & $\bar{X}$ (b) (mm) & $\bar{X}(\mathbf{t})(\mathrm{mm})$ & $\mathbf{R}_{\mathbf{d} \text { (teórico) }}$ metal de base ( $\mathrm{MPa}$ ) & $\mathbf{R}_{\mathbf{d} \text { (teórico) }}$ metal de solda (MPa) \\
\hline CP1 & 4,38 & 2,73 & 102.816 & 66.000 \\
\hline CP2 & 4,6 & 3,04 & 102.816 & 79.617 \\
\hline CP3 & 4,61 & 2,99 & 102.816 & 78.308 \\
\hline CP4 & 6,64 & 4,65 & 102.816 & 121.783 \\
\hline CP5 & 7,58 & 5,34 & 102.816 & 139.854 \\
\hline CP6 & 6,75 & 4,73 & 102.816 & 123.878 \\
\hline
\end{tabular}

Os gráficos de tensão versus deformação de cada corpo de prova estão ilustrados na Figura 6 , onde Rd mostra a tensão gerada durante o ensaio na região soldada. Observa-se, nos corpos de prova 1,2 e 3, uma tensão na região soldada maior que a tensão de ruptura do metal base; tal efeito ocorre devido à a área útil da solda ser inferior à seção do metal base, mostrando que o corpo de prova irá romper-se na região soldada. Nos corpos de prova 4,5 e 6, a linha Rd está abaixo da linha de ruptura do metal base, assim ratifica que o metal base irá romper-se, pois a área útil da região soldada é maior que a área do metal base. 

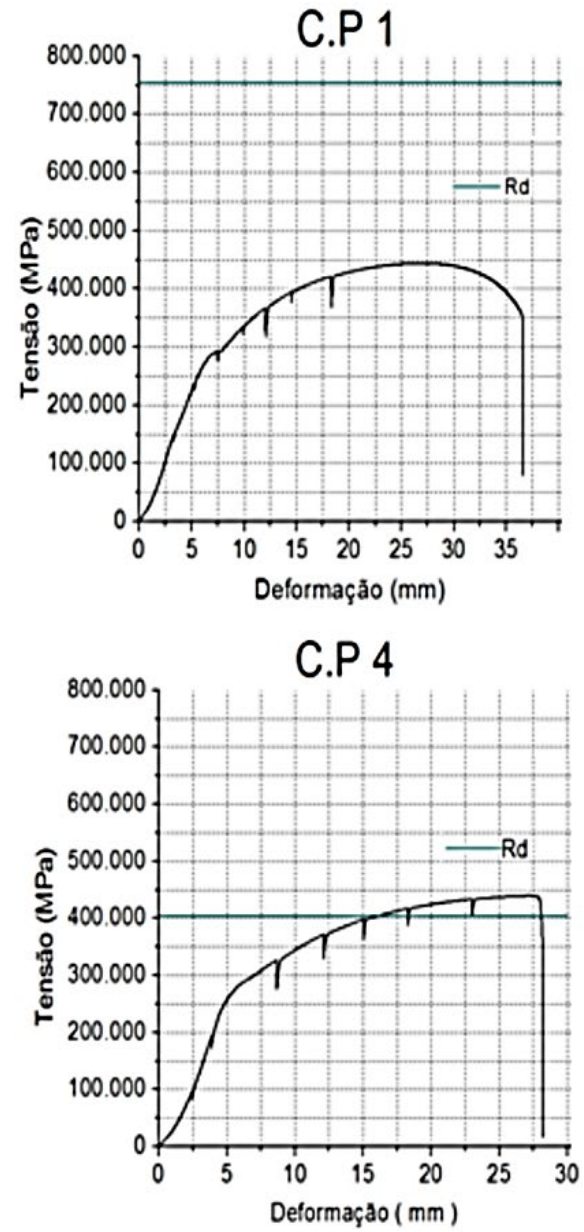
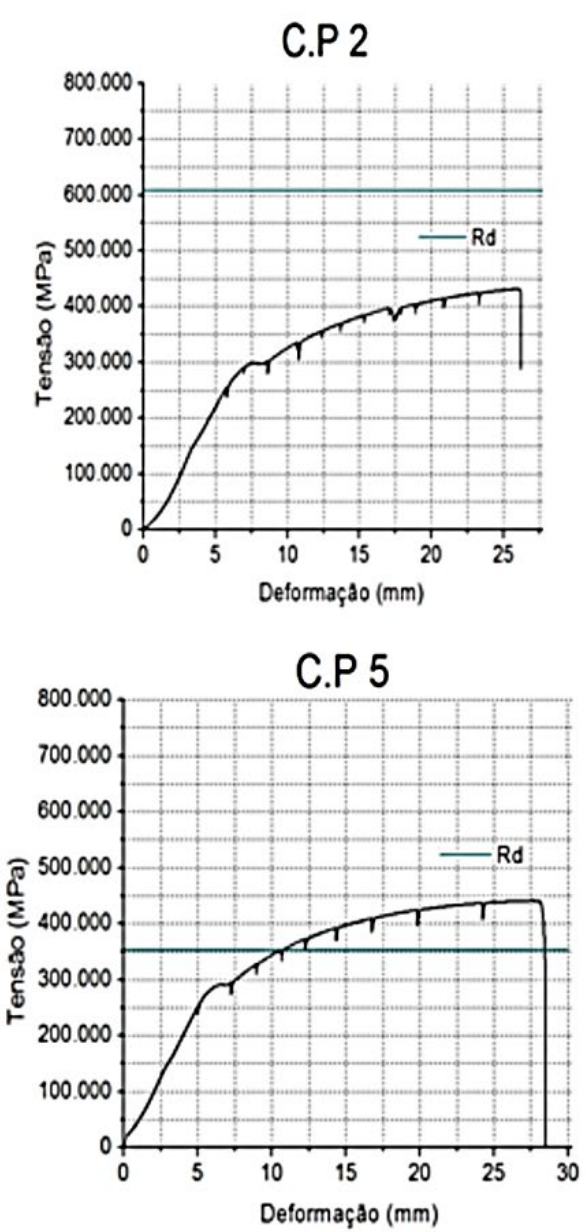

C.P 3

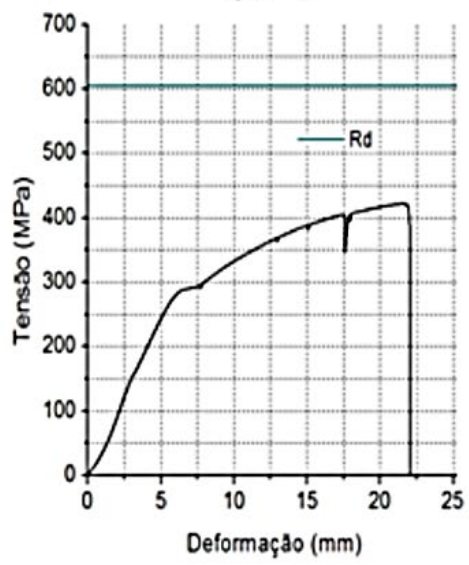

C.P 6

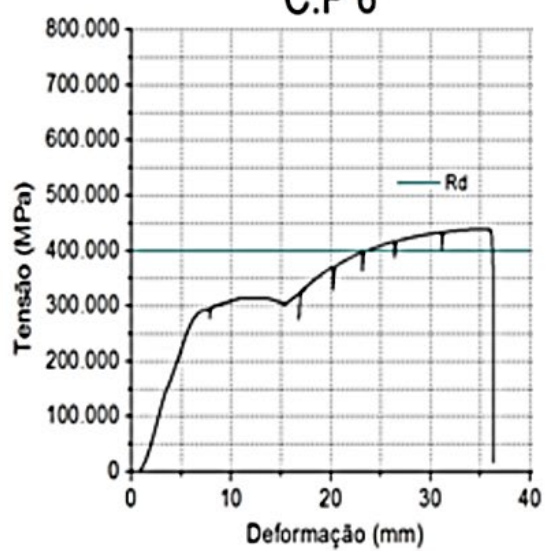

Figura 6. Resultados do ensaio de tração com linha do cálculo teórico, onde: (a) CP1, (b) CP2 e (c) CP3, média das pernas menores que 5 mm, e (d) CP4, (e) CP5,(f) CP6, média das pernas maiores que $5 \mathrm{~mm}$.

Apesar de ter sido observada a presença de descontinuidades na Figura 5-f, o resultado de limite de resistência no ensaio de tração do corpo de prova 3 ficou muito próximo ao corpo de prova 2 . No entanto, foi o corpo de prova com os menores valores de resistência mecânica de tração dos três primeiros corpos de prova.

A relação do tamanho de perna com a tensão gerada na solda está ilustrada na Tabela 5 . Observam-se que as dimensões abaixo da norma sempre tendem a ter uma tensão maior que a tensão de ruptura relacionada à tensão gerada no metal base.

Tabela 5. Comparação de resultados experimental e teórico convertido em tensão.

\begin{tabular}{|c|c|c|c|c|c|}
\hline Corpo de prova & $\bar{X}$ (b) (mm) & $\bar{X}(\mathbf{t})(\mathbf{m m})$ & \multicolumn{2}{|c|}{$\mathbf{R}_{\mathrm{d} \text { (experimental) }}$ metal de solda ( $\mathrm{MPa}$ ) } & $\mathbf{R}_{\mathrm{d} \text { (teórico) }}$ metal de solda ( $\mathrm{MPa}$ ) \\
\hline $\mathrm{CP} 1$ & 4,38 & 2,73 & 443 & 838 & 756 \\
\hline $\mathrm{CP} 2$ & 4,6 & 3,04 & 431 & 674 & 626 \\
\hline $\mathrm{CP3}$ & 4,61 & 2,99 & 421 & 671 & 637 \\
\hline $\mathrm{CP} 4$ & 6,64 & 4,65 & 439 & 449 & 409 \\
\hline $\mathrm{CP} 5$ & 7,58 & 5,34 & 441 & 393 & 357 \\
\hline CP6 & 6,75 & 4,73 & 429 & 432 & 703 \\
\hline
\end{tabular}

As correlações entre a tensão exercida na solda teórica e experimental e a tensão média de ruptura do metal base estão demonstradas na Figura 7. Observa-se que os corpos de prova 4 e 6 estão dentro da faixa de ruptura do metal base teoricamente, mas experimentalmente a tensão é maior na região soldada; porém a ruptura ocorreu no metal base pois o material depositado durante a soldagem é mais resistente mecanicamente. A condição ideal está no corpo de prova 5 onde a tensão exercida experimentalmente na solda é inferior a tensão exercida no metal base. 


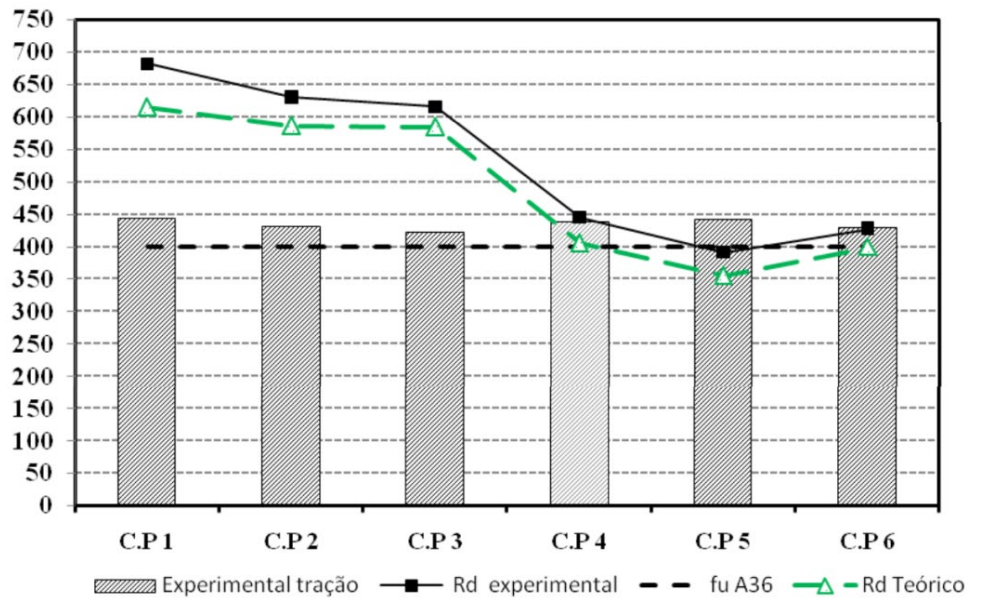

Figura 7. Gráfico do ensaio de tração, demonstrando a tensão atuante na solda.

Conforme as equações teóricas, sabemos que em uma chapa com limite de resistência de 400 MPa, o tamanho mínimo da perna tem que ser 5,60 mm (a norma especifica $5 \mathrm{~mm}$ ). Com a perna de 5,60 mm, a resultante das forças se anula, ou seja, caso a perna da solda for menor que 5,60 mm, a tensão atuante será maior que o limite de resistência da solda causando assim seu rompimento; para soldas maiores que 5,60 mm, a tensão atuante é maior que o limite de resistência do metal de base, causando sua ruptura. Ou seja, uma perna maior que 5,60 mm é necessária teoricamente para que a solda não frature.

Os conceitos apresentados na Figura 8 acima demonstra onde a curva do experimental e do teórico são menores que o limite de resistência do eletrodo. Tanto a linha $\mathrm{f}_{\mathrm{w}}$ experimental e $\mathrm{f}_{\mathrm{w}}$ teórico foram traçadas no gráfico, sendo possível determinar que a perna é de $5 \mathrm{~mm}$ conforme a norma.

Com os resultados obtidos, é possível traçar, conforme a Figura 8, a relação do tamanho da perna teórico e experimental com o especificado pela norma. Utilizando a Equação 5 e multiplicando um fator de resistência para o eletrodo de 0,60 para o experimental, e de 0,567 para o teórico, é possível verificar que em ambos os casos para a resistência atuante na solda a perna não pode ser inferior a 5mm, conforme a NBR 8800:2008; no entanto, ao dimensionar a estrutura, deve-se utilizar o fator teórico que é menor, obtendo assim uma tensão menor sobre a solda.

\section{TEÓRICO x EXPERIMENTAL}

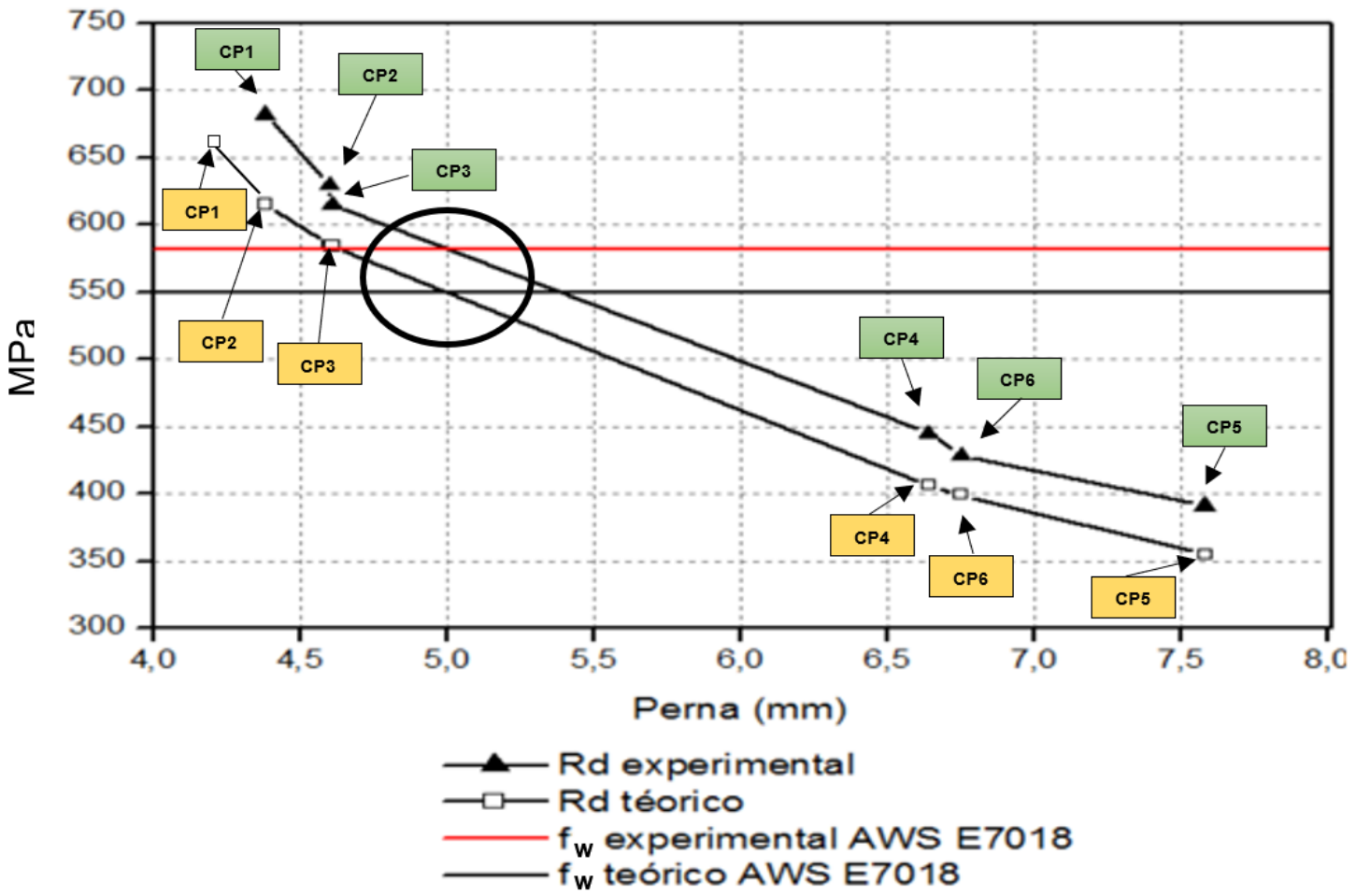

Figura 8. Gráfico experimental e teórico relacionando tensão da solda com a dimensão da perna. 
Os resultados das simulações dos ensaios de tração por elementos finitos dos corpos de prova com perna de $4 \mathrm{~mm}$ e $5 \mathrm{~mm}$ estão apresentadas na Figura 9a e 9b, respectivamente.

O corpo de prova com perna de $4 \mathrm{~mm}$ (Figura 9a) apresentou alta deformação, principalmente na região do filete de solda, explicitando uma deformação e tensão de Von Misses com magnitude de $527 \mathrm{MPa}$ (considerado os resultados dos ensaios de tração do metal base), ou seja, ocorrendo a fratura do corpo de prova ante a força concentrada de 110 kN. Portanto, conforme as simulações, este corpo de prova não seria aceito de acordo com a norma ABNT NBR 8800:2008 [4].
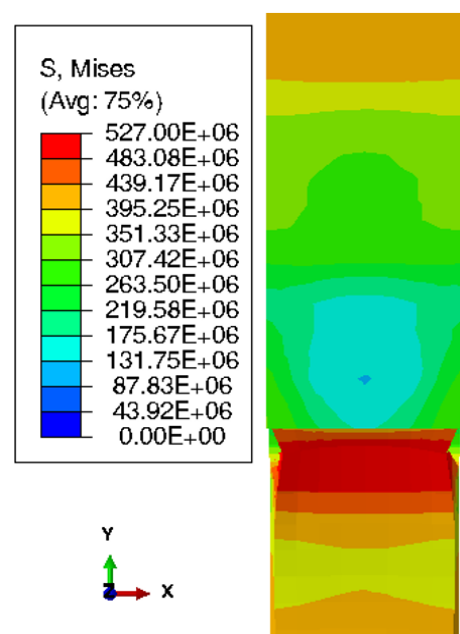

(a)
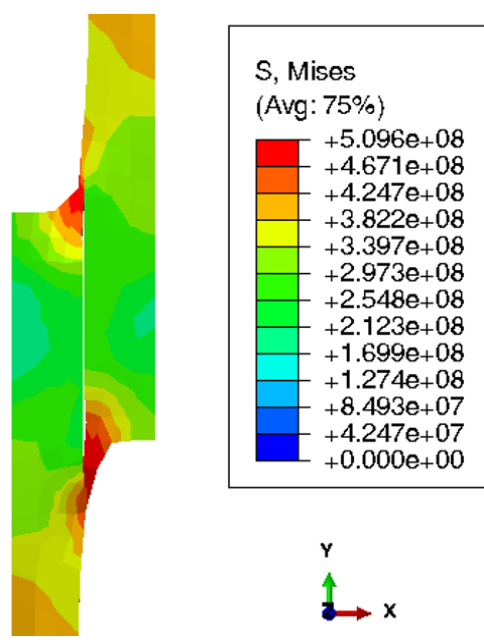

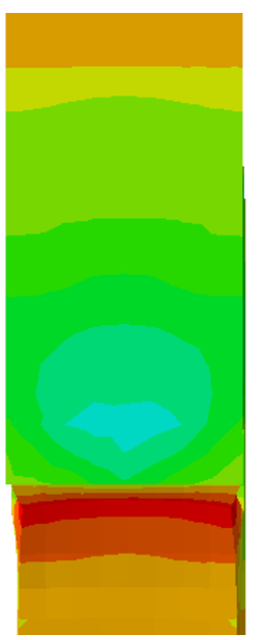

(b)

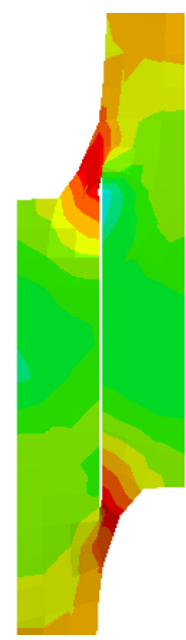

Figura 9. Resultado das tensões de Von Misses das simulações para os corpos de prova com perna de (a) 4 mm e (b) 5 mm.

O corpo de prova com perna de $5 \mathrm{~mm}$ também apresentou (Figura 9b) concentração de tensões de tração localizada na parte dos cordões de solda de filete. Portanto, em ambos os corpos de prova, foi apresentada deformação plástica (principalmente na região do filete), possivelmente com a consequente fratura, considerando a força de 110 kN. Não obstante, caso o processo de soldagem tenha ocorrido com bons procedimentos, o limite de resistência do cordão de solda pode estar maior do que os $510 \mathrm{MPa}$, ocorrendo somente a deformação plástica e sem a ocorrência de fratura.

Os resultados das simulações dos ensaios de tração por elementos finitos dos corpos de prova com perna de $6 \mathrm{~mm}$ e $7 \mathrm{~mm}$ estão apresentadas na Figura 10a e 10b, respectivamente. A partir destas dimensões de perna de soldagem ocorre a transição de concentração de tensões para o metal base.

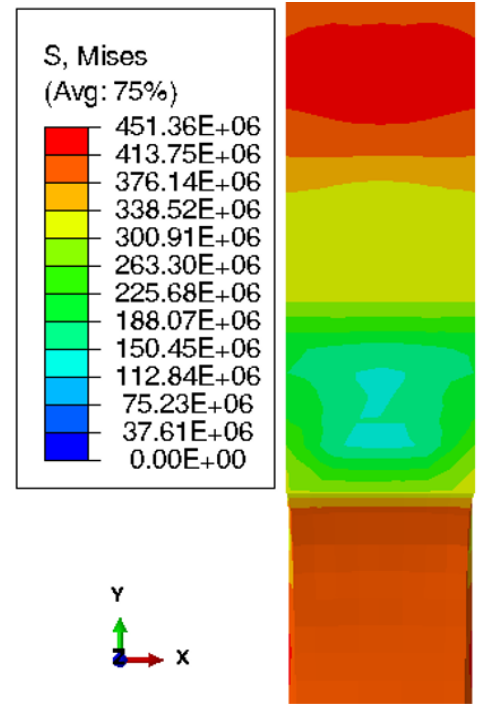

(a)

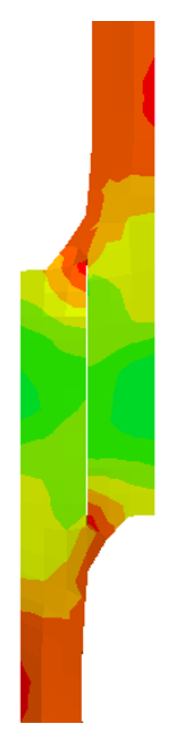

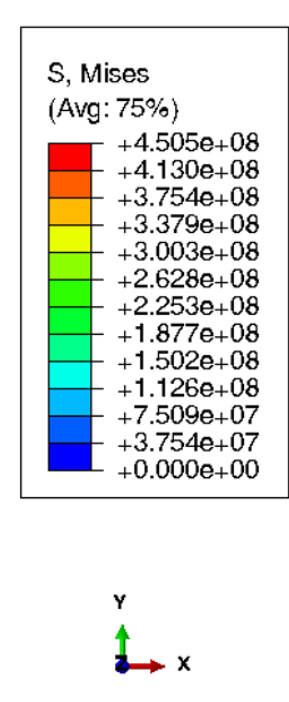
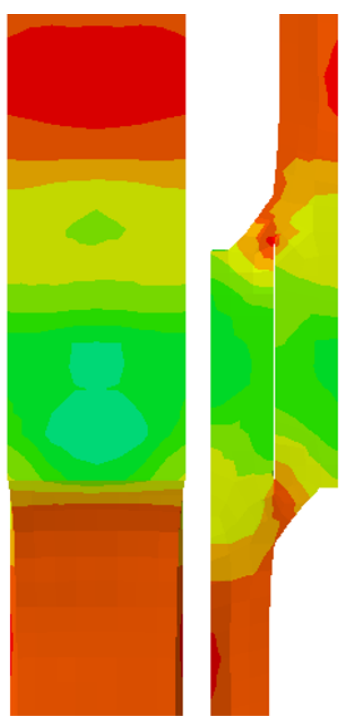

(b)

Figura 10. Resultado das tensões de Von Misses das simulações para os corpos de prova com perna de (a) $6 \mathrm{~mm}$ e (b) $7 \mathrm{~mm}$. 
Ambos os corpos de prova, apresentados na Figura 10, mostraram que há ainda tensão de tração na solda de filete, fato ocorrido devido à geometria de concentração de tensões do contato entre os limites das duas chapas.

Além disso, há tensão maior do que o limite de escoamento tanto na solda quanto no metal base, ocorrendo a deformação plástica; porém não há fratura dos corpos de prova. Pelas simulações, fica evidente que filete com $7 \mathrm{~mm}$ (Figura $10 \mathrm{~b}$ ) possui dimensões suficientes para que a tensão de tração fique concentrada na região do metal base, apesar de atingir o limite de escoamento. Estes dados estão de acordo com os ensaios realizados, pois os corpos de prova com $7 \mathrm{~mm}$ de perna romperam na região do metal base.

Finalmente, conforme previamente mencionado, o limite de resistência do cordão de solda deve ser maior do que 485 $\mathrm{MPa}$, mostrando, portanto, que, para estas geometrias/material de solda, não ocorrerá a fratura na região do filete, no ponto de vista mecânico. Obviamente, estes resultados somente se referem aos casos em que os procedimentos de soldagem estejam dentro do padrão aceitável de qualidade e não ocorra algum fator de alteração metalúrgica.

Na Figura 11 estão demonstrados os corpos de prova após o ensaio de tração. Como analisado na simulação computacional, os corpos de prova com tamanhos de pernas menores que $5 \mathrm{~mm}$ romperam na junção da solda onde há maior tensão concentrada, podendo ser observado que a trinca se propaga na região da junção da perna com o metal base. Inclusive, observa-se nas Figuras 11c e 11d que a fratura do corpo de prova ocorreu na região do filete de solda.

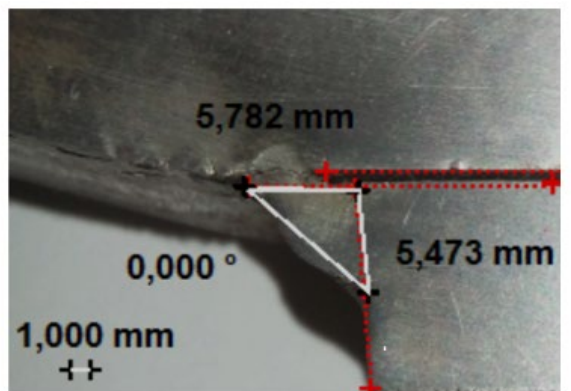

(a)

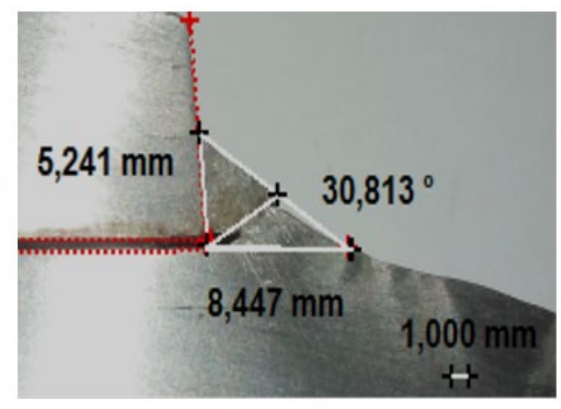

(b)

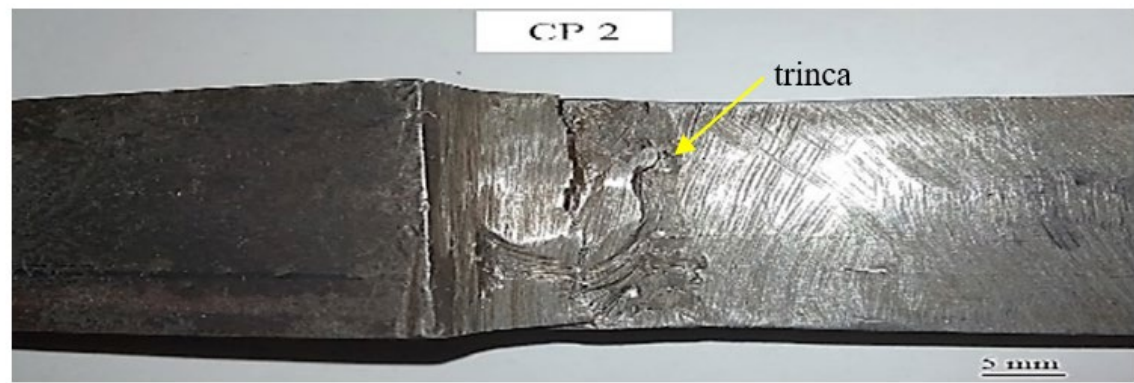

(c)

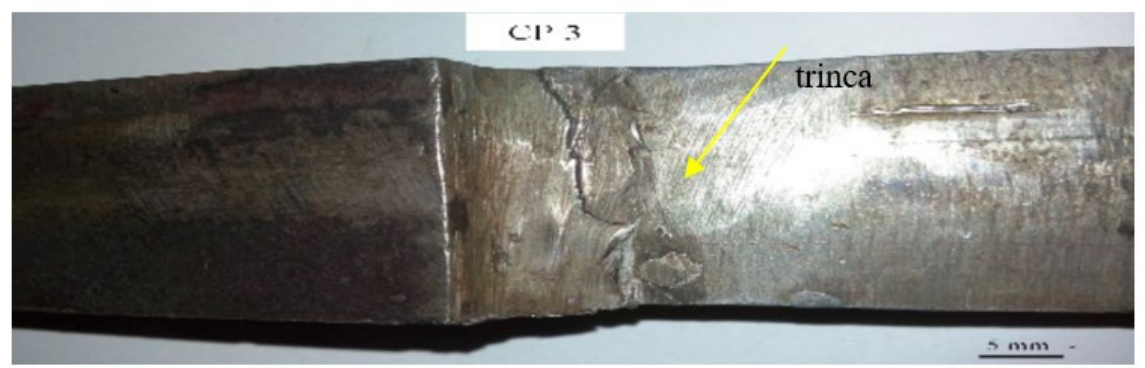

(d)

Figura 11. Corpo de prova que romperam na solda durante ensaio de tração. Onde (a) CP2 vista lateral com ângulo na ruptura da solda, (b) CP3 vista lateral com ruptura do cordão e ângulo, (c) CP2 vista superior com trinca total do cordão de solda e (d) CP3 vista superior com trinca total do cordão de solda.

Os corpos de prova que não se romperam na solda foram analisados com ensaios não destrutivos de líquido penetrante para identificação de trincas e o local de rompimento. Observa-se, na Figura 12, que a região soldada é significantemente afetada, pois o ensaio revelou trincas na região da junção da perna com o metal base, demonstrando a efetividade da análise computacional que demonstrou um acúmulo de tensão em tal região. 


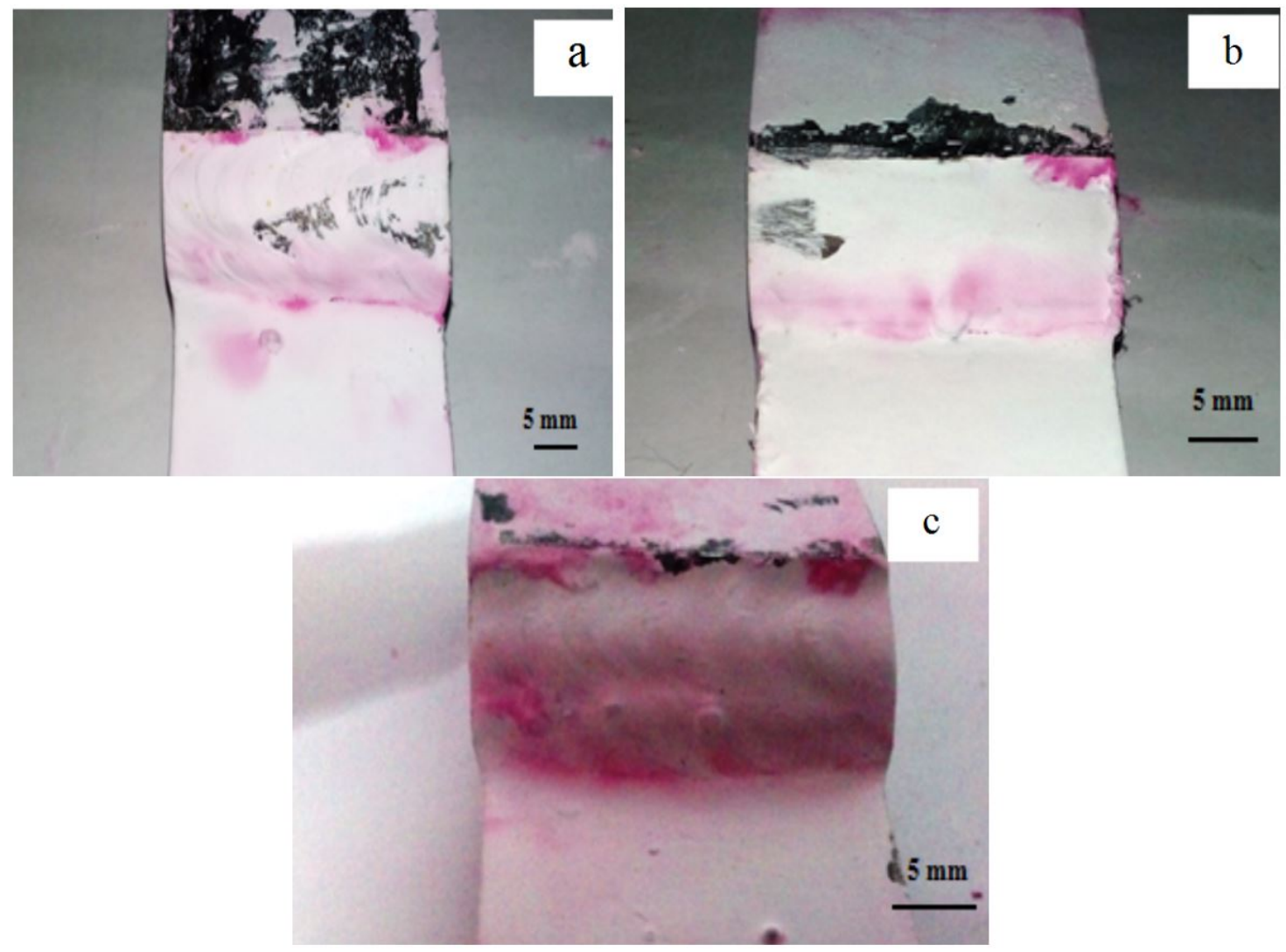

Figura 12. Ensaio de líquido penetrante nos cordões de solda dos corpos de prova que romperam no metal de base (a) CP4 lado A (b) CP5 lado A (c) CP6 lado A.

Adicionalmente, fica evidente que os corpos de prova com menores dimensões de pernas romperam na zona fundida. É percebido, no caso do CP2, mostrado na Figura 13a, que há uma deformação plástica aparente na zona fundida e que ocorre a fratura de maneira perpendicular à direção das tensões de tração.

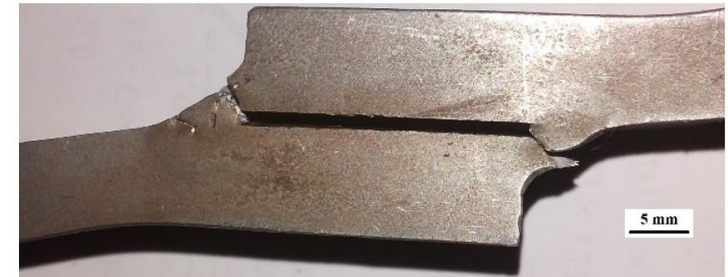

(a)

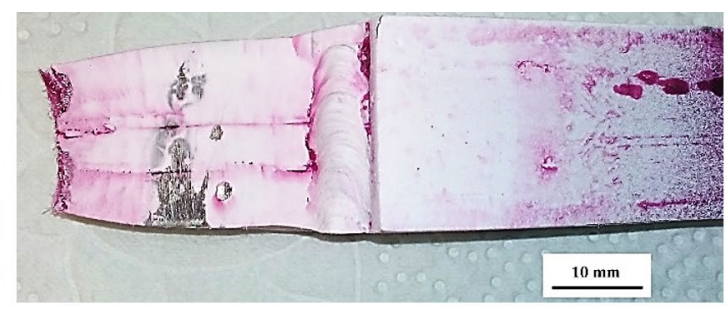

(b)

Figura 13. Aspecto geral após o ensaio de liquido penetrante, evidenciando o local de fratura localizada do CP2 e do CP 5 , localizadas na zona fundida e no metal base, respectivamente. Identifica-se estriç̧ão decorrente da deformação plástica do ensaio uniaxial de tração.

Finalmente, as soldas com maiores pernas romperam no metal base, sendo possível identificar (Figura 13b) estricção decorrente de deformação plástica macroscópica durante o ensaio uniaxial de tração. Nestas condições, a região da zona fundida e da zona afetada pelo calor permaneceram sem alteração aparente, representando que esta geometria/microestrutura de fato possuía maior resistência do que o próprio metal base.

\section{Conclusões}

Comparando os resultados obtidos com os dados especificados na norma, chegamos à conclusão de que os cálculos gerados pela equação de cisalhamento da seção efetiva são cofiáveis. Porém, com os resultados adquiridos com os ensaios de tração chegou-se a uma equação que pode prever a tensão exercida no cordão pelo tamanho da perna soldada. As simulações numéricas confirmaram os resultados experimentais, mostrando que, para as soldas com perna de até $5 \mathrm{~mm}$, a tensão e a deformação se concentrariam na região do cordão de solda de filete, enquanto que, para perna maior do que 6 mm, a tensão 
se distribuiria no metal base. O modelo de elementos finitos também previu a região; em que iria ocorrer a fratura, seria no cordão de solda de filete, principalmente devido à concentração de tensões por fatores geométricos.

\section{Referências}

[1] Bellei IH, Pinho FO, Pinho MO. Edifícios de múltiplos andares em aço. 2. ed. São Paulo: Editora Pini Ltda; 2008.

[2] Pfeil W, Pfeil M. Estruturas de aço: dimensionamento prático de acordo com a NBR 8800:2008. 8. ed. Rio de Janeiro: Editora LTC; 2009.

[3] Machad IG. Dimensionamento de juntas soldadas de filete: uma revisão crítica. Soldagem e Inspeção. 2011;16(2):189-201. http://dx.doi.org/10.1590/S0104-92242011000200011.

[4] Associação Brasileira de Normas Técnicas - ABNT. ABNT NBR 8800:2008 - Projeto de estruturas de aço e de estruturas mistas de aço e concreto de edifícios. Rio de Janeiro: ABNT; 2008.

[5] Pinheiro ACFB. Estruturas metálicas. 2. ed. São Paulo: Blucher; 2005.

[6] Marques PV, Modonesi PJ, Bracarense AQ. Soldagem - fundamentos e tecnologia. 3. ed. Editora UFMG, 2014.

[7] Okumura T, Tanigushi C. Engenharia de soldagem e aplicações. Rio de Janeiro: Editora LTC; 1982.

[8] Budynas RG, Nisbett K. Shigley's mechanical engineering design. $8^{\text {th }}$ ed. New York: McGraw-Hill; 2008.

[9] American Society for Testing and Materials - ASTM. ASTM A36: Standard Specification for Carbon Structural Steel. West Conshohocken: ASTM; 2005.

[10] American Welding Society - AWS. AWS A5.1: Specification for Carbon Steel Electrodes for Shielded Metal Arc Welding. Miami: AWS; 2012. 